\title{
Editorials
}

\section{Shaping up Europe}

During a few days in mid November 2006, a historic event occurred in Istanbul, Turkey, the WHO Ministerial Meeting on Counteracting Obesity. Ministers and ministerial representatives from most of the 53 countries in the European Region of WHO, as well as representatives of the European Commission, met with observers, nongovernmental organisations and temporary advisers. A highprofile document, The European Charter on Counteracting Obesity, was produced and adopted during the meeting ${ }^{1}$.

\section{Content of Charter}

The Charter points out a number of areas where action is needed in order to make it possible to reverse the trend of increasing obesity by 2015 :

- High political will and commitment - as well as collaboration between relevant ministries.

- Health impact assessment in major political decisions, whether dealing with transport or trade, agriculture or city planning.

- Support for local authorities in their local preventive work.

- Linkage to sustainable development strategies and noncommunicable disease prevention strategies.

- Social responsibility and individual responsibility balance.

- Regional coordination of policy measures in order not to shift unhealthy foods to other countries due to marketing pressures, with WHO pointed out as the obvious coordinator.

- Use of culturally relevant messages.

- Increase in public awareness.

- Attention given to vulnerable groups and low socioeconomic groups to ensure they are not exploited by commercial activities and that the healthy choice is made the easy choice.

- Collaboration with the food industry as well as with others in the private sector.

No concrete objectives are set up in the Charter. A European Action Plan will follow, which will be based on a set of background reports that will be continuously disseminated.

\section{Areas and actors}

In each country the health sector and thereby the health ministry is suggested to take the lead, and all governmental sectors are mentioned as important partners, none more important than the other. Monitoring and surveillance are mentioned in the Charter as areas which need serious improvement in order to correctly monitor progress. Certainly, more intervention studies are needed with a proper design to make them sufficiently valid to be included in systematic reviews, possibly including costeffectiveness measures. At a time in which we see obesity prevention nominated as a public health priority, we have only a limited number of studies from which to examine findings'. The European Charter includes the following statement regarding the evidence base: 'Sufficient evidence exists for immediate action; at the same time, search for innovation, adjustment to local circumstances and new research on certain aspects can improve the effectiveness of policies'.

European public health nutritionists are holding their breath. Research and education are mentioned only briefly in the Charter. Capacity building in public health nutrition is not mentioned at all. Certainly, governments need to realise that in order to keep up the evidence base on what works, money is needed for intervention research - needs which are currently not addressed by the European Commission research directorate. Furthermore, not very much can happen locally or nationally unless a workforce is available to do the work. A huge demand will emerge for experts who can help out in the monitoring of success of upcoming efforts. Will our finance ministers be easily convinced when it comes to the allocation of funds to public health nutrition training and research? Hopefully, the European Charter will be successful in gaining continued political will and commitment from the health ministries of Europe and, probably most important of all, from finance ministers. New possibilities for research and training programmes in our area may be on the horizon in Europe.

\section{Agneta Yngve}

Editor-in-Chief

\section{References}

1 European Charter on Counteracting Obesity. WHO European Ministerial Conference on Counteracting Obesity, 'Diet and Physical Activity for Health', Istanbul, Turkey, 15-17 November 2006. Available at http://www.euro.who.int/ Document/E89567.pdf. Accessed 1 December 2006. 